\title{
Distribution of Ingested and Injected Radiocopper in Two Patients with Menkes' Kinky Hair Disease
}

\author{
ANNE W. LUCKY ${ }^{(32)}$ AND Y. EDWARD HSIA ${ }^{(33)}$ \\ Departments of Human Genetics and Pediatrics, Yale University School of Medicine, New Haven, Connecticut, USA
}

\begin{abstract}
Summary
The distribution of ${ }^{64} \mathrm{Cu}$ is reported in whole blood, plasma fractions, urine, and stool in an adult volunteer and two patients with Menkes' kinky hair disease (trichopoliodystrophy) after intragastric and iv administration. In the adult, after oral ${ }^{64} \mathrm{Cu}$, circulating ${ }^{64} \mathrm{Cu}$ showed an initial peak at $40-60$ min which was $4 \%$ of the total dose (or $5 \%$ of the amount calculated to be absorbed), a small secondary peak at $3.5 \%$ by $4 \mathrm{hr}$, then a gradual rise to $32 \mathrm{hr}$. Approximately $55 \%$ of the whole blood radioactivity was in the plasma from 8-48 hr. In the two patients, after ingestion or injection, there was no early blood peak and about $10 \%$ of both the absorbed or injected copper persisted in the circulation from the 4th hr to beyond $24 \mathrm{hr}$ in a pattern similar to that in the adult, but less than $40 \%$ of the ${ }^{64} \mathrm{Cu}$ was in the plasma fraction after $4 \mathrm{hr}$. In all subjects, the albumin/globulin ratio of radioactivity fell progressively, suggesting prompt ceruloplasmin synthesis by the liver. No radioactivity was detected in cerebrospinal fluid $10 \mathrm{hr}$ after ${ }^{64} \mathrm{Cu}$ injection in patient 2 . Urinary excretion of ${ }^{64} \mathrm{Cu}$ in the adult appeared to be linear after $6 \mathrm{hr}$ (approximately $0.08 \%$ of the total dose per $24 \mathrm{hr}$ ). In patient 1 , it was half as great $(0.04 \% / 24$ hr), but if calculated on the assumption that only $6 \%$ of ingested copper was absorbed in patient 1 , his urinary excretion rate, $0.67 \% / 24 \mathrm{hr}$ would be eight times that of the control, strongly suggestive of renal inability to conserve copper. In the adult, stool radioactivity totaled $24 \%$ of the ingested dose by $48 \mathrm{hr}$. In patient 1 , stool radioactivity was already $94 \%$ by 48 hr and in patient 2 , after iv ${ }^{64} \mathrm{Cu}$, stool radioactivity was only $2.8 \%$ by $96 \mathrm{hr}$. This low stool radioactivity after injected copper indicated minimal biliary loss of radiocopper, and ruled out a rapid enterohepatic recycling of copper in this disease. Because $94 \%$ of a physiologic dose of ${ }^{64} \mathrm{Cu}$ was in the 48 -hr stool in patient $1,<8 \%$ of his ingested copper could have been absorbed, compared with over $80 \%$ in the adult control. This confirms that there is an absorption defect for copper in Menkes' disease, resulting in approximately $10 \%$ of normal copper uptake.
\end{abstract}

\section{Speculation}

The data are interpreted as confirming that there is a mucosal block to copper absorption in Menkes' disease, but that this block is incomplete. Despite depleted circulating copper, erythrocyte uptake appeared normal or high in these patients, and hepatic incorporation into ceruloplasmin seemed to be unimpaired. There may be renal transport abnormalities in Menkes' disease as well, because of the unexpectedly high urinary ${ }^{64} \mathrm{Cu}$ excretion in the presence of hypocupremia. Perhaps an abnormality of blood-brain copper distribution is responsible for the severe neurologic features of this disease.

Menkes' kinky-hair disease (trichopoliodystrophy) is an Xlinked recessively inherited condition associated with infantile seizures, profound psychomotor retardation, cerebrocerebellar degeneration, hypopigmentation, tortuous arteries, fragile bones and abnormal hair $(4,21)$. Danks et al. $(9-11)$ first noted that these patients had abnormally low levels of serum copper and ceruloplasmin, unresponsive to oral copper, although parenteral copper would correct the hypocupremia. On the basis of increased copper in jejunal biopsies from from their patients, compared to infants with nonspecific diarrhea, they postulated a defect in the mucosal transport of copper. Clinical trials of parenteral copper, even from early infancy, have failed to correct or reverse the neurological sequelae $(5,12,15,19)$. Thus, this condition is not due to a simple mucosal block with consequent copper deficiency. One paradoxical observation has been the absence of anemia and neutropenia in all but one of these patients (1) despite their severe hypocupremia. This is in contrast to infants and adults with nutritional hypocupremia who have severe hematologic manifestations with marked lethargy and hypotonia $(2,3,18)$, but not the grave neurologic abnormalities or the pili torti of Menkes' disease (16, 22,25 ).

Dekeban et al. (12) have studied the fate of ${ }^{67} \mathrm{Cu}$ in three patients with Menkes' disease. Two further cases are reported in which the distribution of ${ }^{64} \mathrm{Cu}$ was followed in whole blood, plasma fractions, urine, and stool, after intragastric and iv administration.

\section{PATIENTS}

Patient 1 , a black male, was 18 -months-old at the time of study (Fig. 1); his clinical presentation has been reported previously (27). He was born $3 \mathrm{wk}$ early after premature rupture of membranes, his birth weight was $3.3 \mathrm{~kg}$, his Apgar was 10 . The neonatal period was complicated by transient mild hyperbilirubinemia. His mother reported that he had normal development until age 4 months, when he was holding up his head, looking about, but not yet turning over. At that age, he was first hospitalized for seizures and had several episodes of hypothermia with temperatures of $35^{\circ} \mathrm{C}$. A pneumoencephalogram showed dilated ventricles, a brain biopsy was nondiagnostic, and long bone $\mathrm{X}$-rays showed metaphyseal flaring. His hair showed microscopic pili torti. His eyes were blue, although his parents and both sisters had brown eyes. The diagnosis of Menkes' was considered and a serum copper was found to be $19 \mu \mathrm{g} / \mathrm{dl}$. He continued to have numerous minor motor seizures, not responsive to anticonvulsant medication. His development had regressed by the time of study to having only a sucking reflex. There was no family history of similar disease. His serum copper has ranged from 10-19 $\mu \mathrm{g} / \mathrm{dl}$ (normal 75-135), his serum ceruloplasmin from 2-16 IU (normal 35-65), and his urine copper excretion was as low as $6 \mu \mathrm{g} / 24 \mathrm{hr}$ (normal $<50$ for adults).

Patient 2, a while male, was 5-years-old at the time of study (Fig. 2). He was the first child of healthy parents who had no family history of this condition. In infancy, he fed poorly and had episodes of hypothermia and frequent infections. At age 6 months, he presented with seizures, hypotonia, and the characteristic hair findings diagnostic of Menkes' syndrome (Fig. 3). Further studies revealed hypocupremia with serum copper ranging from 20-58 $\mu \mathrm{g} / \mathrm{dl}$, serum ceruloplasmin was 6-17 IU, and urine copper was as low as $2 \mu \mathrm{g} / 24 \mathrm{hr}$. His neurologic status has declined progressively 


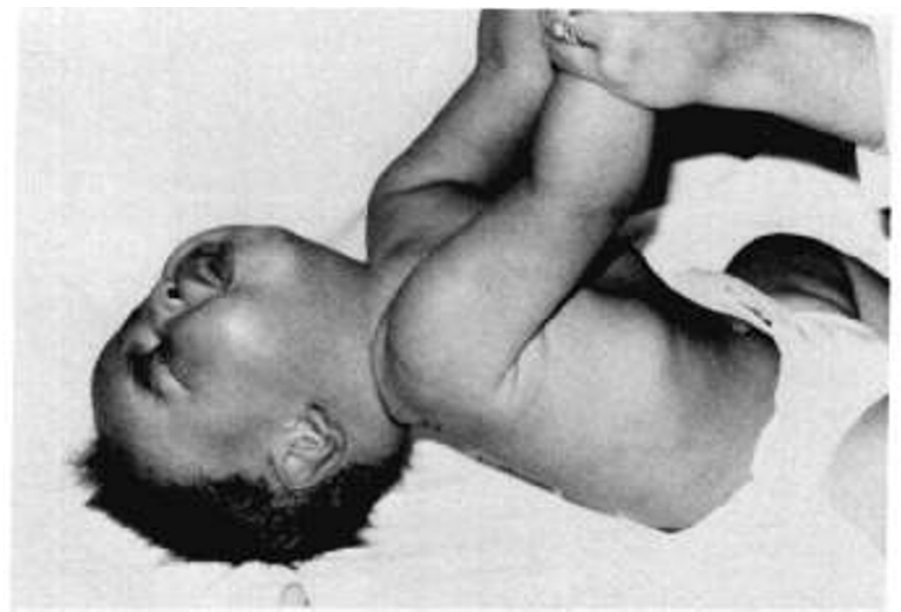

Fig. 1. Patient 1: age, 18 months. Note poor head control and abnormal hair.

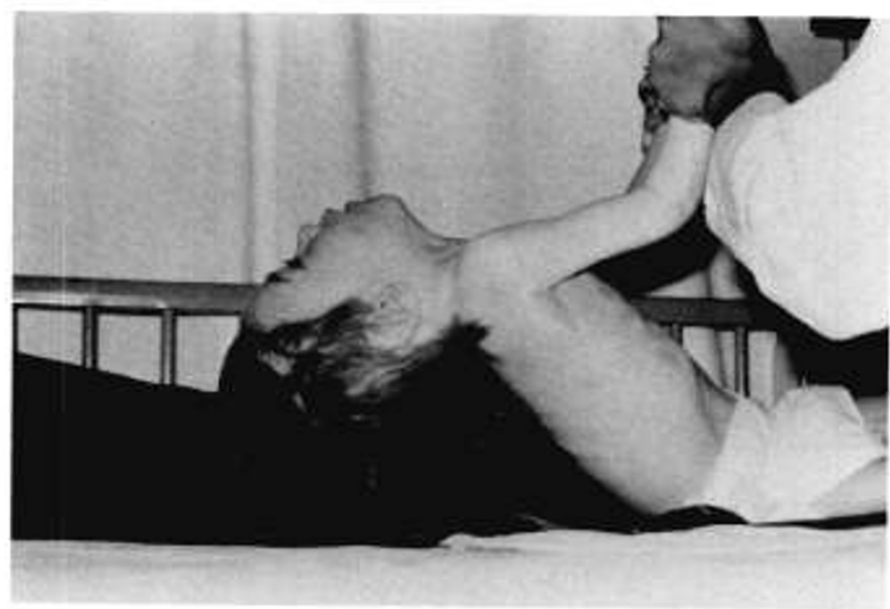

Fig. 2. Patient 2: age, 5 yr. Note poor head control.

with loss of all developmental milestones, uncontrollable seizures, and need for nasogastric feeding.

The adult subject was a 42-year-old male in good health.

\section{MATERIALS AND METHODS}

Radioactive copper ${ }^{64} \mathrm{Cu}(28)(\mathrm{T} 1 / 2=12.8 \mathrm{hr})$ was supplied as cupric nitrate in $1 \mathrm{~N}$ nitric acid, $25-30 \mathrm{mCi} / \mathrm{mg}$ at time of delivery. For oral and intragastric administration, the calculated dose of ${ }^{64} \mathrm{Cu}$ was diluted in $10 \mathrm{ml}$ of $0.9 \%$ saline, and given after an overnight fast (without breakfast). For iv administration, the solution was brought to neutral $\mathrm{pH}$ by titration with $1.2 \mathrm{M}$ sodium bicarbonate, diluted in $0.9 \%$ saline, and then passed through a $0.22 \mu$ millipore filter; then, after testing for pyrogenicity in a rabbit, $4 \mathrm{ml}$ were infused iv over $10 \mathrm{~min}$ into patient 2 with no adverse reactions. The dose of elemental copper was estimated to be less than $30 \%$ of each subject's daily dietary copper (Table 1). Heparinized venous whole blood samples were counted for radioactivity on a gamma spectrometer (29) adjusted for ${ }^{64} \mathrm{Cu}$. Plasma was counted separately. Portions of plasma were centrifuged through ultrafilters (30) at $3000 \times g$ to separate ultrafiltrable from protein-bound copper; other portions were mixed with an equal volume of saturated ammonium sulfate for $1 \mathrm{hr}$ at $20^{\circ} \mathrm{C}$ and centrifuged at $10,000 \times g$ for $20 \mathrm{~min}$. The supernatant (defined as the albumin fraction), and the precipitate (defined as the globulin fraction which contains ceruloplasmin, an $\alpha$-globulin), were counted. Each urine voided and each $24-\mathrm{hr}$ collection of stool (incinerated to a fine ash [31]) was also counted. Standard ${ }^{64} \mathrm{Cu}$ samples were counted with each batch to calibrate and monitor the decay rate of radioactivity.

Plasma volume was determined in the two subjects with $\mathrm{I}^{125}$ albumin. Total circulating radiocopper was calculated by multiplying concentration times estimated blood volume, (plasma volume $) \times(1$-hematocrit $) / 1$. Hepatic uptake of radioactivity was assessed by gamma-scanning.

Results are expressed as the percent of the initial dose or of the absorbed dose of ${ }^{64} \mathrm{Cu}$ calculated to be in the total circulating blood volume at each time point. The cellular fraction was the difference between whole blood and (plasma radioactivity) $\times(1$ hematocrit).

Informed consent, specifying that these studies would have no therapeutic benefit for the patients, was obtained from the parents or legal guardians of the children, and from the male adult subject. The studies were approved by the Yale Radiation Safety and Human Investigation Committees.

\section{RESULTS}

\section{PRELIMINARY FINDINGS}

In a preliminary experiment, $26 \mu \mathrm{g}$ of ${ }^{64} \mathrm{Cu}$ (initial radioactivity, $440 \mu \mathrm{Ci}$ ) was administered via nasogastric tube to each of the patients. Circulating radioactivity was readily measurable; and was about $0.1 \%$ of the administered dose by $20 \mathrm{~min}$ rising to a plateau of $0.2 \%$ (patient 1 ) and $0.3 \%$ (patient 2) from $8-24 \mathrm{hr}$. A jejunal biopsy $(20 \mathrm{mg})$ at $4 \mathrm{hr}$ in patient $2 \mathrm{had}$ no detectable radioactivity. (The specimen would have to contain at least 10 times the radioactivity of an equal volume of blood for any to be detected.) Electron-microscopy of a portion of this specimen revealed no structural abnormalities of the jejunal mucosa. Gammascanning at $6 \mathrm{hr}$ revealed diffuse radioactivity in the abdomen, but no concentration over the liver. Urine radioactivity was also detectable, about $0.01 \%$ of the absorbed dose being excreted by 4 $\mathrm{hr}$, and $0.02 \%$ by $9 \mathrm{hr}$.

\section{INTRAGASTRIC ${ }^{64} \mathrm{CU}$ IN PATIENT I}

After a steady rise in total circulating radioactivity to a peak at $4 \mathrm{hr}$ of $0.55 \%$ of the administered dose, there was a gradual

Table 1. Doses of ${ }^{64} \mathrm{Cu}$ given

\begin{tabular}{cccl} 
Subject & Copper $(\mu \mathrm{g})$ & ${ }^{64} \mathrm{Cu}(\mu \mathrm{Ci})$ & Route \\
\hline Case 1 & 26 & 740 & Gastric \\
Case 2 & 8.6 & 275 & iv \\
Control & 31 & 880 & Oral \\
\hline
\end{tabular}

' Radioactivity at time of administration.

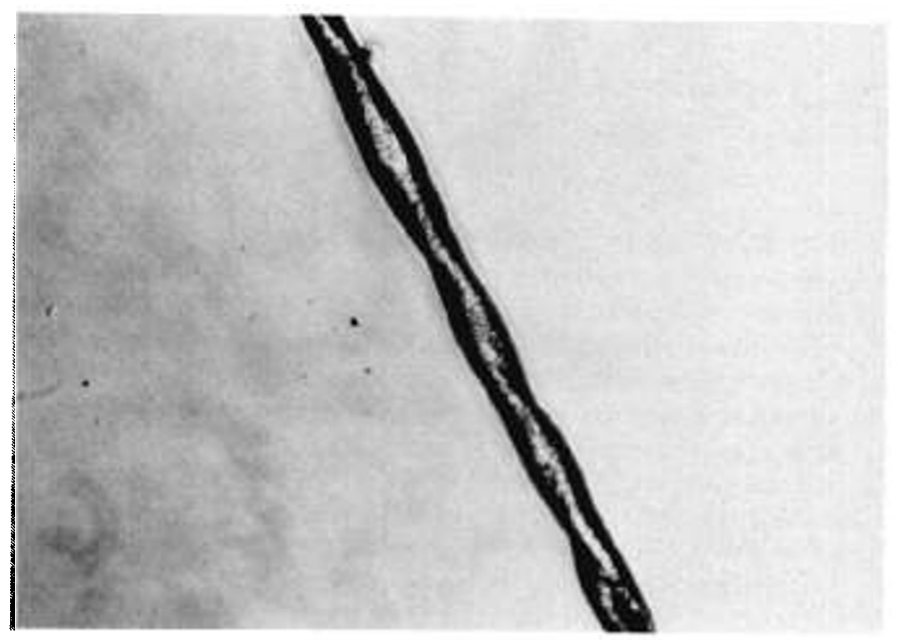

Fig. 3. Hair from patient 2 shows the classic pili torti. 


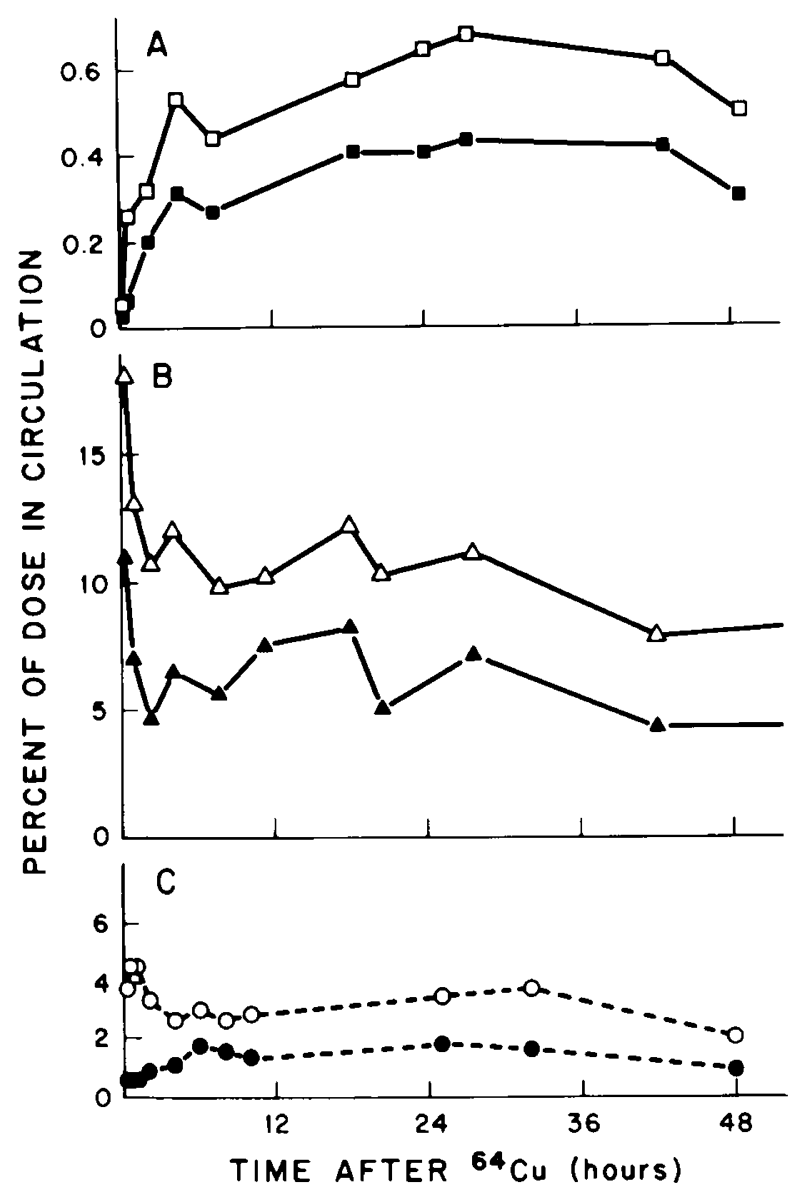

Fig. 4. Distribution of circulating radioactivity in whole blood and plasma. The symbols represent percent of administered radioactive dose calculated to be in the circulation at each time point in whole blood (open symbols) and cellular fraction (closed symbols). $A$ : intragastric ${ }^{64} \mathrm{Cu}$ in case 1 (squares); $B$ : iv ${ }^{64} \mathrm{Cu}$ in case 2 (triangles); $C$ : oral ${ }^{64} \mathrm{Cu}$ in adult (circles). The vertical scales are adjusted to be proportionate to the absorbed fraction of the administered dose ( $6 \%$ for case $1,100 \%$ for case $2,80 \%$ for the adult)

secondary rise to $0.6 \%$ by $28 \mathrm{hr}$. The distribution of radioactivity in the whole blood (Fig. 4a, 5), showed less than $40 \%$ in the plasma fraction after $4 \mathrm{hr}$. The plasma ultrafiltrate (presumably amino acid-bound copper) had detectable radioactivity throughout the $24 \mathrm{hr}$; the albumin/globulin radioactivity ratio was about 0.40 for the first $4 \mathrm{hr}$, this then decreased to $<0.08$ by $42 \mathrm{hr}$.

Urine excretion of ${ }^{64} \mathrm{Cu}$ (Fig. 6) was approximately linear at the rate of $0.04 \% / 24 \mathrm{hr}$ of the administered dose. Stool radioactivity (Fig. 7) was already $83 \%$ of the administered dose by $10 \mathrm{hr}, 94 \%$ by $48 \mathrm{hr}$, and greater than $99 \%$ by $72 \mathrm{hr}$.

\section{IV ${ }^{64} \mathrm{Cu}$ IN PATIENT 2}

Circulating radioactivity (Fig. $4 \mathrm{~b}$ ) fell rapidly to $10 \%$ of the administered dose by $8 \mathrm{hr}$, rose to $12 \%$ by $16 \mathrm{hr}$, then declined to $8 \%$ by $48 \mathrm{hr}$. The proportion of whole blood radioactivity in plasma, after the first $2 \mathrm{hr}$, was similar to that after ingested ${ }^{64} \mathrm{Cu}$ in patient 1 . Less than $1 \%$ of plasma radioactivity, however, was found in the ultrafiltrate at $2 \mathrm{hr}$ (Fig. 5) and none by $18 \mathrm{hr}$; the albumin/globulin ratio was 0.78 at $2 \mathrm{hr}$ and $0.14 \mathrm{at} 18 \mathrm{hr}$. Two ml of cerebrospinal fluid, obtained at $10 \mathrm{hr}$, had no detectable radioactivity (if the specimen. had $>1 \%$ of the radioactivity in $2 \mathrm{ml}$ of blood or plasma, it would have been measurable). Intense hepatic radioactivity was shown by gamma-scanning at $8 \mathrm{hr}$, but not at 96 $\mathrm{hr}$ (after eight half-lives, when only intense concentrations would have remained detectable)

Urine excretion of ${ }^{64} \mathrm{Cu}$ (Fig. 6) was not linear. The excretion rate was about $0.6 \% / 24 \mathrm{hr}$ for the first $4 \mathrm{hr}$, but after $24 \mathrm{hr}$, the rate had declined to $<0.04 \% / 24 \mathrm{hr}$. Stool radioactivity (Fig. 7 ) was very low, $<1.5 \%$ of the iv dose had appeared in the stool by $48 \mathrm{hr}$ and $2.8 \%$ by $96 \mathrm{hr}$.

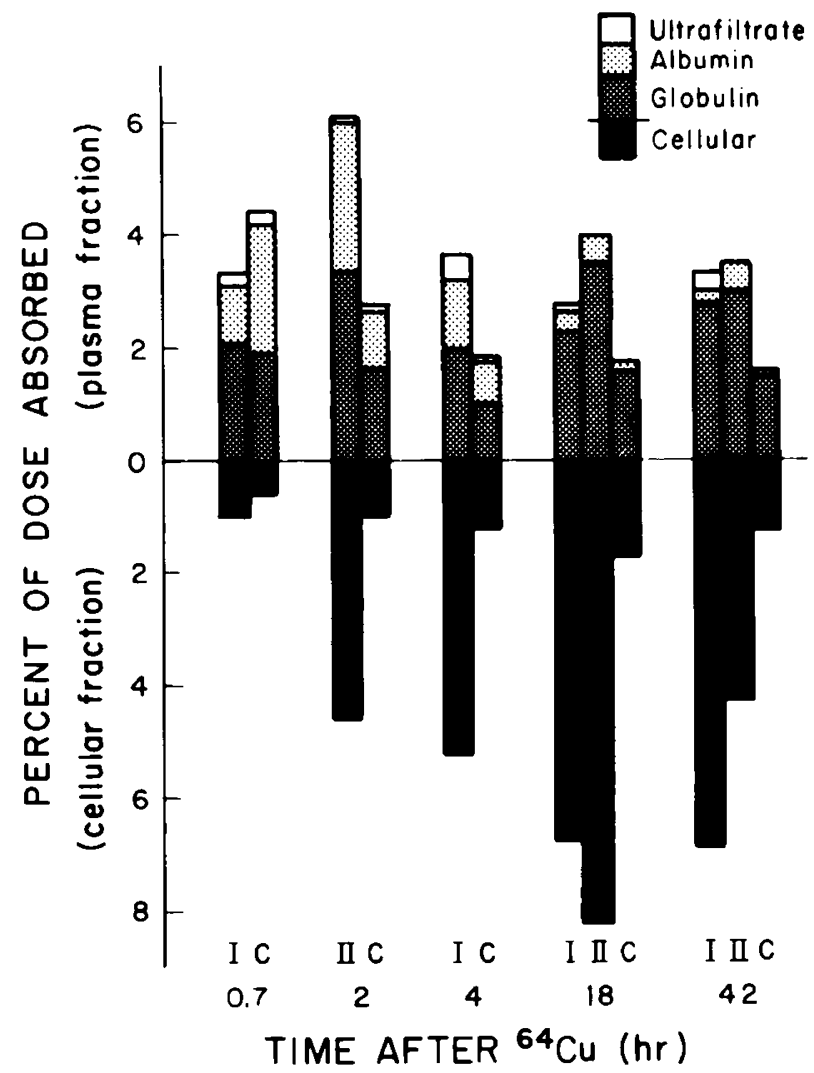

Fig. 5. Distribution of radioactivity in blood fractions. Radioactivity in the cellular fractions are plotted below the ordinate, and the ultrafiltrate, albumin and globulin fractions above the ordinate. $\mathrm{I}=$ intragastric ${ }^{64} \mathrm{Cu}$ in case $1, \mathrm{II}=\mathrm{iv}{ }^{64} \mathrm{Cu}$ in case $2, \mathrm{C}=$ oral ${ }^{64} \mathrm{Cu}$ in adult. Note that no data are presented for case 1 at $2 \mathrm{hr}$ or for case 2 at $40 \mathrm{~min}$ and $4 \mathrm{hr}$. The vertical scale has been adjusted to represent percent of the estimated absorbed radioactivity.

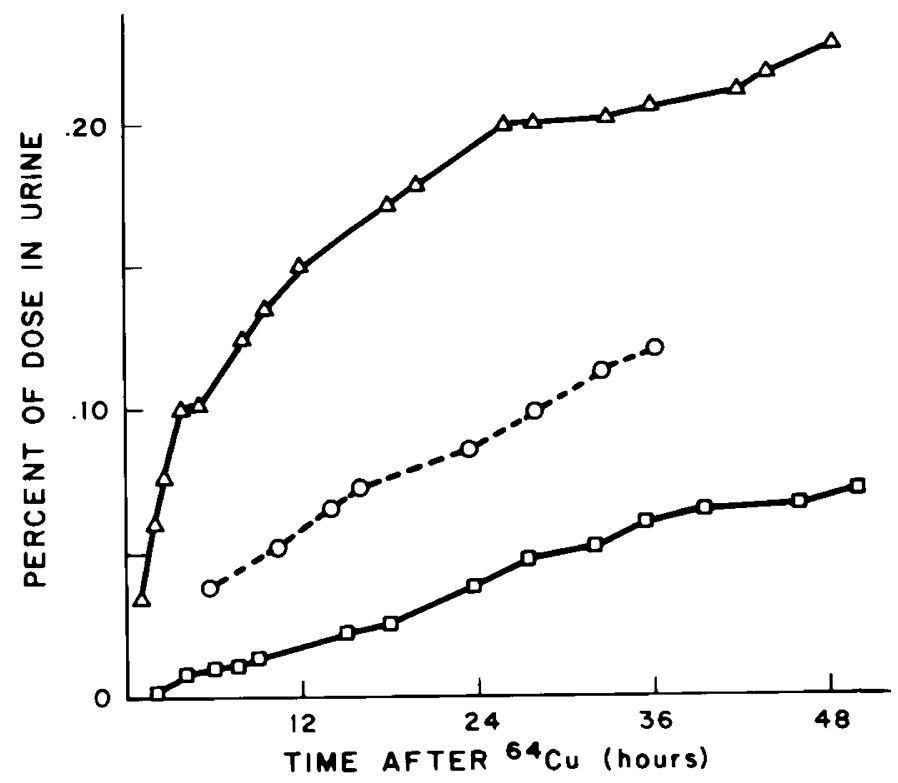

Fig. 6. Radioactivity recovered in urine. Cumulative recovery of radioactivity in urine after intragastric ${ }^{64} \mathrm{Cu}$ in case 1 (squares), iv ${ }^{64} \mathrm{Cu}$ in case 2 (triangles), and oral ${ }^{64} \mathrm{Cu}$ in the adult (circles). The vertical scale represents percent of administered dose. 


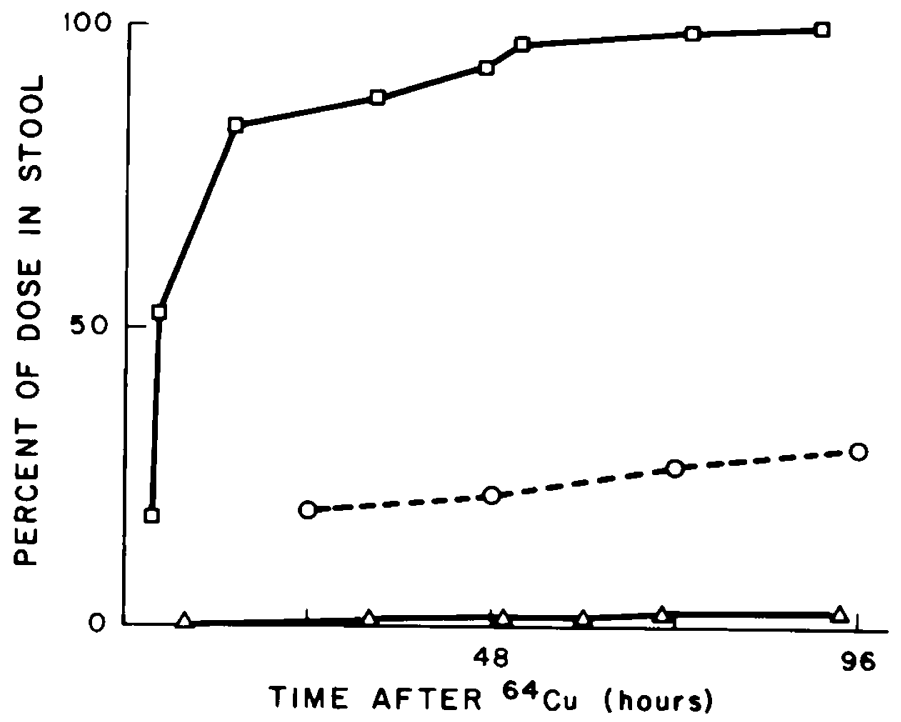

Fig. 7. Radioactivity recovered in stool. Cumulative recovery of radioactivity in the stool; the symbols are the same as for Figure 6.

\section{ORAL ${ }^{64} \mathrm{Cu}$ IN THE ADULT}

Circulating ${ }^{64} \mathrm{Cu}$ (Fig. 4c) showed an initial peak at 40-60 min, which was $4 \%$ of the total dose (or $5 \%$ of the absorbed ${ }^{64} \mathrm{Cu}$ ), a smaller peak of $3.5 \%$ by $4 \mathrm{hr}$, then a very gradual rise until $32 \mathrm{hr}$. The plasma radioactivity (Figs. $4 \mathrm{c}, 5$ ) declined to $50 \%$ of whole blood at $8 \mathrm{hr}$, after which it remained steady at about $55 \%$. The ultrafiltrate contained $4 \%$ of plasma radioactivity at $2 \mathrm{hr}$ declining to $2 \%$ at $18 \mathrm{hr}$ (Fig. 5); the albumin/globulin ratio fell to 0.60 by $2 \mathrm{hr}$ and 0.14 by $18 \mathrm{hr}$. Hepatic uptake of ${ }^{64} \mathrm{Cu}$ was intense by gamma-scanning both at $4 \mathrm{hr}$ and at $48 \mathrm{hr}$.

Urine excretion of ${ }^{64} \mathrm{Cu}$ (Fig. 6) appeared to be linear after $6 \mathrm{hr}$, at the rate of about $0.08 \% / 24 \mathrm{hr}$ of the ingested dose. Stool radioactivity was $20 \%$ of the ingested dose by $24 \mathrm{hr}, 24 \%$ by $48 \mathrm{hr}$ and $30 \%$ by $96 \mathrm{hr}$ (Fig. 7).

\section{DISCUSSION}

Normally (13), as illustrated by the findings in the adult control, a major portion of the $3-6 \mathrm{mg}$ /day of dietary copper is absorbed from the intestine. Of circulating copper, a small fraction is ionically bound to plasma amino acids (23), a large fraction is absorbed to albumin, most plasma copper is covalently bound to ceruloplasmin, and another large fraction is bound to metallothioneins in the red cell $(6,7,13,23,24,26)$. Radiocopper tracer studies have shown intensive hepatic uptake of copper in the first $4 \mathrm{hr}$, followed by retention in liver cells and incorporation into ceruloplasmin for recirculation in the globulin fraction of plasma, or excretion into the bile. In normal subjects, $8-10 \%$ of injected or $20-80 \%$ of ingested radiocopper ends up in the stool in the first few days $(7,13,26)$. Radiocopper uptake by other tissues is minimal compared with hepatic uptake. Even with intestinal reabsorption of biliary copper, the major route of copper excretion eventually is via the bile into the stool, so stool copper content nearly equals food copper, $<50 \mu \mathrm{g} /$ day being lost in the urine, and smaller amounts through the skin. Urine recovery of injected radiocopper is normally $0.1-0.3 \%$; of ingested radiocopper, it is $0.06-0.18 \%(7,20,26)$.

In Menkes' disease, the abnormally low stool radioactivity found in case 2 after injected ${ }^{64} \mathrm{Cu}$ indicates reduced biliary loss of copper, and rules out any rapid enterohepatic recycling of copper. Because $94 \%$ of a physiologic dose of ingested ${ }^{64} \mathrm{Cu}$ was in the 48-hr stool in patient 1 (and some still remained in his abdomen, probably in his colon) $<6 \%$ of his ingested copper was absorbed compared with over $80 \%$ in our adult control (who would already have excreted some absorbed ${ }^{64} \mathrm{Cu}$ into his bile [7, 13]). This confirms that there is an absorptive defect for copper in
Menkes' disease, resulting in approximately $10 \%$ of normal copper uptake.

Comparison of circulating and urinary ${ }^{64} \mathrm{Cu}$ after injected and ingested copper showed interesting similarities in these patients. Assuming that only $6 \%$ of the ingested dose in patient 1 was absorbed, after the 4th hr, a higher proportion of absorbed ${ }^{64} \mathrm{Cu}$ was in his circulation, particularly in his cellular fraction, than in the adult (Fig. 5). There was a similar disproportionate excess of radioactivity in the whole blood and cellular fraction of patient 2 after inejcted ${ }^{64} \mathrm{Cu}$. The persistence of radioactivity in the ultrafiltrate of patient 1 after ingested ${ }^{64} \mathrm{Cu}$ (Fig. 5) can be attributed to prolonged uptake from his intestine. Although the radioactivity in the crude ammonium sulfate precipitate would be contaminated by trapped albumin, shifts in radioactivity from the supernatant to the precipitate must be indicative of shifts in the distribution of copper between albumin ceruloplasmin (excluding the remote possibility of an abnormal copper binding globulin). Both after ingested and injected ${ }^{64} \mathrm{Cu}$, a definite shift of radioactivity from the albumin fraction into the globulin fraction was suggestive of prompt ceruloplasmin synthesis by the liver. This concurs with other reports of normal hepatic synthesis of ceruloplasmin in Menkes' disease $(5,15,19)$.

The differences between early urinary excretion of ingested copper and injected copper in the two patients is accounted for by the slow uptake of ingested ${ }^{64} \mathrm{Cu}$ versus the sharp uptake of injected ${ }^{64} \mathrm{Cu}$. As a proportion of the administered dose, the rate of urinary excretion in Menkes' was about half of the adult's, but when calculated on the assumption that only $6 \%$ of ingested copper was absorbed in patient 1 , his urinary excretion rate, $0.67 \% / 24 \mathrm{hr}$, would be eight times that of the adult, strongly suggestive of renal inability to conserve copper in Menkes' disease.

These data are consistent with those of Dekaban et al. (12) who used ${ }^{67} \mathrm{Cu}\left(\mathrm{T} \mathrm{L}^{1 / 2}=61.7 \mathrm{hr}\right)$ and also found decreased absorption, increased urine excretion, and preferential uptake by red cells.

Finally, in some preliminary experiments, unpublished evidence is available that in vitro uptake of ${ }^{64} \mathrm{Cu}$ by the patient's red cells, suspended either in their own or in control plasma, was equal to or greater than that of normal subjects. Cultured cells from our patients (Milunsky et al., unpublished data) have shown the same increased copper content reported by Goka et al. (14). The abnormal distribution and turnover of radiocopper we have demonstrated in vivo correlate well with in vitro evidence that the molecular defect in Menkes' disease must be due to abnormal cellular transport or retention of copper $(8,17)$.

\section{REFERENCES AND NOTES}

1. Adams, P. C.. Strand, R. D., Bresnan, M. J., and Lucky, A. W.: Kinky hair syndrome: serial study of radiological findings with emphasis on the similarity to the battered child syndrome. Radiol., 112: 401 (1974).

2. Al-Rashid, R. A., and Spangler, J.: Neonatal copper deficiency. N. Engl. J. Med., 285: 841 (1971)

3. Ashkenazi, A., Levin, S., Djaldetti, M., Fishel. E., and Benvenisti, D.: The syndrome of neonatal copper deficiency. Pediatrics, 52: 525 (1973).

4. Bray, P. F.: Sex-linked neurodegernerative disease associated with monolithrix. Pediatrics, 36: 417 (1965).

5. Bucknall, W. E., Haslam, R. H. A., and Holtzman, N. A.: Kinky hair syndrome: response to copper therapy. Pediatrics, 52: 653 (1973).

6. Bush, J. A., Mahoney, J. P., Gubler, C. J., Cartwright. G. E., and Wintrobe, M. M.: Studies on copper metabolism XXI: the transfer of radiocopper between erythrocytes and plasma. J. Lab. Clin. Med., 47: 898 (1956).

7. Cartwright, G. E., and Wintrobe, M. M.: Copper metabolism in normal subjects. Am. J. Clin. Nutr., 14: 224 (1964).

8. Chan, W. Y., Garnica, A., and Rennert, O.: Defective metallothionein (MT) and copper $(\mathrm{Cu})$ accumulation in Menkes kinky hair syndrome (MKHS) fibroblasts. Am. J. Hum. Genet., 29: 29A (1977)

9. Danks, D. M.: Steely hair, mottled mice and copper metabolism. N. Engl. J. Med., 293: 1147 (1975).

10. Danks, D. M., Cartwright, E., Stevens, B. J., and Townley, R. R. W.: Menkes' kinky hair disease: Further definition of the defect in copper transport. Science,

179: 1140 (1973).
11. Danks, D. M., Stevens, B. J., Campbell, P. E., Gillespie, J. M., Walker-Smith, J., Blomfield, J., and Turner, B.: Menkes' kinky-hair syndrome. Lancet, 1: 1100 (1972).

12. Debakan, A. S., Aamodt, R., Rumble, W. F., Johnston, G. S., and O'Reilly, S. Kinky hair disease: study of copper metabolism with use of ${ }^{67} \mathrm{Cu}$. Arch Neurol., 32: 672 (1975).

13. Evans, G. W.: Copper homeostasis in the mammalian system. Physiol. Rev., 53: 
14. Goka, T. J Stevenson, R. E., Heffernan, P. M. and Howell, R. R.: Menkes disease: a biochemical abnormality in cultured human fibroblasts. Proc. Natl. Acad. Sci., (USA), 73: 604 (1976).

15. Grover, W. D., and Scrutton, M. C.: Copper infusion therapy in trichopoliodystrophy. J. Pediatr., 86: 216 (1975).

16. Hirano A. Llena, J. F., French, J. $\mathrm{H}$., and Ghatak, N. R.: Fine structure of the cerebellar cortex in Menkes' kinky-hair disease. Arch. Neurol., 34: 52, (1977).

17. Horn, N.: Copper incorporation studies on cultured cells for prenatal diagnosis of Menkes' disease. Lancet, $I: 1156$ (1976).

18. Karpel, J. T., and Peden, V. H.: Copper deficiency in long-term parenteral nutrition. J. Pediatr., 80: 32 (1972).

19. Lott, I. T., DiPaolo, R., Schwartz, D., Janowska, S., and Kanfer, J. N.: Copper metabolism in the steely-hair syndrome. N. Engl. J. Med., 292: 197 (1975).

20. Maytum, W. J. Goldstein, N. P., McGuckin, W. F., and Owen, C. A.: Copper metabolism in Wilson's disease, Laennec's cirrhosis, and hemochromatosis: studies with radiocopper $\left(\mathrm{Cu}^{64}\right)$. Proc. Mayo Clin., 36: 641 (1961).

21. Menkes, J. H., Alter, M., Steigleder, G. K., Weakley, D. R., and Snug, J. H.: A sex-linked recessive disorder with retardation of growth, peculiar hair, and focal cerebral and cerebellar degeneration. Pediatrics, 29: 764 (1962)

22. Mollekaer, A. M.: Kinky hair syndrome. Acta. Paediatr. Scand., 63: 289 (1974)

23. Neumann, P. S., and Sass-Kortsak, A.: The state of copper in human serum evidence for an amino acid bound fraction. J. Clin. Invest., 46: 646 (1967).

24. Shields, G. S., Markowitz, H., Klassen. W. H., Cartwright, G. E., and Wintrobe, M. M.: Studies on copper metabolism XXXI: erythrocyte copper. J. Clin. Invest., 40: 2007 (1961).
25. Singh, A., and Bresnan, M. S.: Menkes' kinky-hair syndrome (trichopoliodystrophy) low copper levels in the blood, hair and urine. Am. J. Dis. Child., 125: 572 (1973).

26. Strickland, G. T., Beckner, W. M., Leu, M. -L., and O'Reilly, S.: Turnover studies of copper in homozygotes and heterozygotes for Wilson's disease and controls: isotope tracer studies with ${ }^{67} \mathrm{Cu}$. Clin. Sci., 43: 605 (1972).

27. Volpintesta, E. J.: Menkes' kinky-hair syndrome in a black infant. Am. J. Dis. Child., 128: 244 (1974)

28. New England Nuclear Corporation

29. Packard.

30. Amicon Centriflo Membrane (CF 50A) Ultrafilters.

31. This work would not have been possible without the assistance of Dr. Richard Spencer and his staff in the Division of Nuclear Medicine and the unstinted support of the staff of the Children's Research Center. Stool incineration used an apparatus devised by Dr. H. Pearson. Patient I was a patient of Dr. E. Volpintesta and patient 2 was a patient of Dr. B. Russman.

32. Requests for reprints should be addressed to: Anne W. Lucky, M. D., Department of Dermatology, LC1 500, Yale Medical School, 333 Cedar Street, New Haven, CN 06510 (USA).

33. The present address of Dr. Y. Edward Hsia is: Departments of Genetics and Pediatrics, University of Hawaii, Honolulu, Hawaii 96822 (USA).

34. This research was supported, in part, by National Institutes of Health Grant HD 00198 CRC-RR-125, and National Foundation Medical Service Grant C-143.

35. Received for publication June 6, 1978

36. Accepted for publication November 27, 1978. 